\title{
Redox-Mediated Regulatory Mechanisms of Endoplasmic Reticulum Homeostasis
}

\author{
Ryo Ushioda ${ }^{1,2}$ and Kazuhiro Nagata ${ }^{1,2}$ \\ ${ }^{1}$ Laboratory of Molecular and Cellular Biology, Department of Molecular Biosciences, Faculty of Life Sciences, \\ Kyoto Sangyo University, Kyoto 603-8555, Japan \\ ${ }^{2}$ Institute for Protein Dynamics, Kyoto Sangyo University, Kyoto 603-8555, Japan \\ Correspondence: ryo3ussy3@cc.kyoto-su.ac.jp; nagata@cc.kyoto-su.ac.jp
}

The endoplasmic reticulum (ER) is a dynamic organelle responsible for many cellular functions in eukaryotic cells. Proper redox conditions in the ER are necessary for the functions of many luminal pathways and the maintenance of homeostasis. The redox environment in the ER is oxidative compared with that of the cytosol, and a network of oxidoreductases centering on the protein disulfide isomerase (PDI)-Ero1 $\alpha$ hub complex is constructed for efficient electron transfer. Although these oxidizing environments are advantageous for oxidative folding for protein maturation, electron transfer is strictly controlled by Ero1 $\alpha$ structurally and spatially. The ER redox environment shifts to a reductive environment under certain stress conditions. In this review, we focus on the reducing reactions that maintain ER homeostasis and introduce their significance in an oxidative ER environment.

$\mathrm{T}_{\mathrm{h}}^{\mathrm{h}}$ he endoplasmic reticulum (ER) is the site of folding for newly synthesized secretory and membrane proteins (Ellgaard and Helenius 2003; Ellgaard and Ruddock 2005). Therefore, various molecular chaperones and folding enzymes for nascent polypeptides exist in the ER. Because approximately one-third of the total proteins produced in whole cells are inserted into the ER (Ghaemmaghami et al. 2003), protein quality control is essential to maintain ER homeostasis. The ER is also a reservoir for intracellular calcium ions and stores $\sim 10,000$ times more calcium ions than the cytosol (Meldolesi and Pozzan 1998b; Groenendyk et al. 2006; Michalak et al. 2009). Intracellular calcium ions released from the ER are one of the most important signaling molecules in the cyto- sol and regulate numerous cellular functions, including muscle contraction, cellular motility, and vesicular transport, via calcium-binding proteins, including calmodulin, in the cytosol (Berridge et al. 2000, 2003). Calcium ions in the lumen of the ER are required for the activities of various molecular chaperones, and enzymes in the ER are also important to maintain protein quality control (Lebeche et al. 1994; Lievremont et al. 1997; Lucero et al. 1998; Argon and Simen 1999; Lucero and Kaminer 1999; Michalak et al. 2009).

Another characteristic feature of the ER environment is that it is oxidative compared with the cytosol (Hwang et al. 1992; Bass et al. 2004; Dixon et al. 2008; Gutscher et al. 2008). This oxidative environment is considered advanta-

Editors: Richard I. Morimoto, F. Ulrich Hartl, and Jeffery W. Kelly

Additional Perspectives on Protein Homeostasis available at www.cshperspectives.org

Copyright (C) 2019 Cold Spring Harbor Laboratory Press; all rights reserved; doi: 10.1101/cshperspect.a033910

Cite this article as Cold Spring Harb Perspect Biol 2019;11:a033910 
geous for the disulfide bond formations required for protein folding. These three major environmental factors, protein quality control, calcium homeostasis, and redox regulation, balance each other and their cross talk maintains ER homeostasis (Fig. 1). Disruptions in ER homeostasis (generally called ER stress) are triggered by an imbalance among these environmental factors in the ER. These failures in ER homeostasis can cause severe diseases, such as neurodegenerative diseases (e.g., Alzheimer's disease) (Salminen et al. 2009), and metabolic disorders, such as type 2 diabetes (Back and Kaufman 2012).

In this review, we introduce the basic features of the oxidative environment in the ER and describe the reduction reactions in the oxidative ER environment. We describe the central role of the disulfide reductase ERdj5 in the cross talk among these three environmental factors (protein quality control, calcium homeostasis, and redox regulation) for maintaining ER homeostasis (Fig. 1).

\section{REDOX ENVIRONMENT OF THE ER}

Glutathione is one of the major components involved in maintaining the redox environment

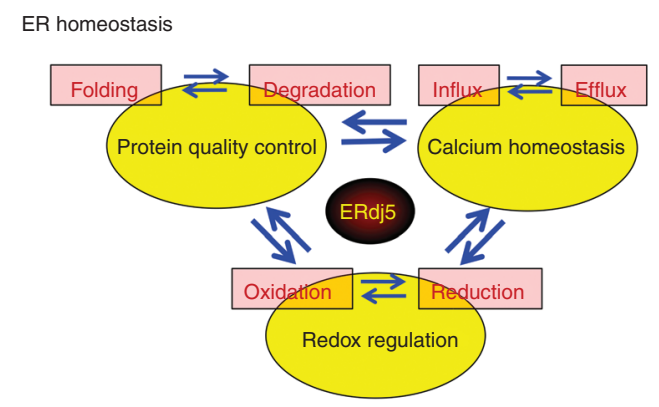

Figure 1. Cross talk among three environmental factors for endoplasmic reticulum (ER) homeostasis. Three characteristic environmental factors and cross talk in ER protein quality control, calcium homeostasis, and redox control are shown. Protein quality control is balanced between "folding" and "degradation," and calcium ion homeostasis is balanced between the "uptake" and "release" of calcium ions. The redox environment is balanced between "oxidation" and "reduction." We introduce the disulfide reductase ERdj5 as a key factor responsible for each cross talk. in both prokaryotic and eukaryotic cells. Glutathione, a tripeptide consisting of glycine, cysteine, and glutamine, is abundant in cells and acts as an electron donor in oxidoreductive reactions. Reduced glutathione (GSH) and oxidized glutathione (GSSG) are in equilibrium and constitute a redox environment in each cellular compartment. In eukaryotic cells, glutathione is present in all organelles, but the glutathione synthesis system is located only in the cytosol (Delaunay-Moisan et al. 2017). This indicates the existence of a system that transports glutathione to each organelle. Indeed, the glutathione concentration in the ER lumen is estimated to be $15 \mathrm{~mm}$, which is higher than that in the whole-cell lysate (7 mM) (Birk et al. 2013; Montero et al. 2013). In addition, GSH has lower redox potential and higher reactivity than the protein disulfide isomerase (PDI) family proteins, a group of oxidoreductases in the ER (Lappi and Ruddock 2011). Therefore, GSH reduces PDI family proteins, and this reduction is coupled with oxidation of GSH to GSSG (as will be described later, an electron is finally transferred to molecular oxygen via Ero1). Glutathione synthesis is limited to the cytosol, and the presence of glutathione reductase in the ER has not yet been detected. Therefore, it is necessary to supply GSH consumed in the oxidative reaction with PDI family proteins and discharge the produced excess GSSG from the ER. However, the existence of active GSH and/or GSSG transporters on the ER membrane has never been reported. Only limited information on a transport system for GSH and/or GSSG across the ER membrane is available. The calcium channel ryanodine receptor has been shown in vitro to transport glutathione through passive transport (de Crouy-Chanel and Richarme 2001; Bánhegyi et al. 2003). Other research groups found that the Sec61p channel, a protein-conducting channel on the ER membrane, is involved in GSH diffusion from the cytosol to the ER (Ponsero et al. 2017). However, it is necessary to maintain GSH in the ER at a higher concentration than that in whole-cell lysates, and, thus, a transporter that actively transports GSH should be assumed but is almost entirely unknown. 


\section{OXIDATIVE FOLDING IN THE ER}

Nascent chains of secretory and membrane proteins synthesized by ribosomes undergo various modifications, such as $\mathrm{N}$-glycosylation and phosphorylation, after insertion into the ER. Disulfide bond formation via cysteines is also a posttranslational modification required for protein folding and maturation (Ellgaard and Helenius 2003). The redox environment of the ER is generally oxidative compared with that of the cytosol; this is one reason the ER is regarded as advantageous as a site for disulfide bond formation. The ratio of GSSG to GSH required to establish the appropriate redox environment is GSSG:GSH $=1: 1$ to $1: 7$ in the lumen of the ER and GSSG:GSH $=1: 10$ to $1: 100$ in the cytosol (Fig. 2; Hwang et al. 1992; Birk et al. 2013; Montero et al. 2013). Therefore, because the GSSG: GSH ratio is higher in the ER than in the cytosol, it is believed to create an oxidative environment.

In addition, $>20$ oxidoreductases represented by PDI exist in the ER and share the thioredoxin-like domain, which may possess catalytic activity for disulfide oxidation, isomerization, or reduction (Andreu et al. 2012; Galligan and Petersen 2012). Although the reasons why so many oxidoreductases are necessary in the ER remain unclear, it is important to establish the diversity of the proteins that partner with each PDI family protein. For example, ERp57 interacts with the lectin-type molecular chaperone calnexin or calreticulin (Okazaki et al. 2000) and contributes to disulfide bond formation or isomerization of glycoproteins (Elliott et al. 1997; Van der Wal et al. 1998; Zapun et al. 1998). P5 interacts strongly with $\mathrm{BiP}$, a major molecular chaperone in the ER, and contributes to disulfide formation in substrates recognized by $\mathrm{BiP}$ (Marciniak et al. 2004; Jessop et al. 2009).

Each oxidoreductase must be oxidized by Ero1 (ER oxidoreductin 1), Erol $\alpha$ and Ero1 $\beta$ in mammalian cells (Cabibbo et al. 2000; Pagani et al. 2000), and Erolp in yeast (Frand and Kaiser 1998; Pollard et al. 1998) with flavin adenine dinucleotide (FAD) as a cofactor. Electrons from the substrates are transferred from several disulfide oxidase enzymes to Erol $\alpha$. However, in these electron transfers, the affinity with Erol differs for each oxidase (Araki et al. 2013). Erol preferentially interacts with PDI, the major oxidase/isomerase in the ER, among other PDI family proteins. Electrons received from PDI are transferred to molecular oxygen via FAD and produce hydrogen peroxide, a reactive oxygen species (ROS) (Fig. 2A; Tu et al. 2000; Tu and Weissman 2002; Wang et al. 2009). Some oxidases in the ER form a network with the Ero1 $\alpha$ PDI complex (Araki et al. 2013). As shown in Figure 2B, Ero1 $\alpha$ and PDI constitute a regulatory hub complex that sequentially oxidizes other oxidoreductases. P5, ERp57, and ERp46 not only transfer electrons directly to Ero $1 \alpha$ but also pave the path for transferring electrons to PDI and delivering electrons to Erol $\alpha$ via PDI. Abundant PDI in the ER acts as an electron acceptor for other oxidoreductases to provide flexibility and robustness in the ER redox environment. The redox network centered on Ero1 $\alpha-P D I$ eventually catalyzes disulfide bonds in each substrate protein and aids in protein maturation. Thus, it is possible that such multiple oxidation pathways contribute to the formation of disulfide bonds in a broad range of substrates by constructing a network for electron transfer from various oxidoreductases to Erol $\alpha$.

Based on this evidence, the Erol $\alpha-P D I$ complex collects many electrons and acts as an acceptor of electrons generated by oxidative folding via PDI and other PDI family proteins in the ER. High levels of hydrogen peroxide produced from oxidative folding affect the redox environment of the ER. Hydrogen peroxide also contributes to the oxidative environment of the ER lumen (Margittai et al. 2012), but hydrogen peroxide accumulation may inhibit correct disulfide formation in the ER. Abnormal formation of disulfide bridges and abnormal intermolecular oligomerization lead to ER stress via accumulation of misfolded proteins, which impairs ER functions by perturbing protein quality control and calcium homeostasis. Hydrogen peroxide is cleared from the ER lumen with peroxidases, including peroxiredoxin 4 (Prx4), glutathione peroxidase (GPx)7, and GPx8. In these elimination systems, the hydrogen peroxide oxidizes PDI, ERp46, ERp57, and P5 through Prx4, GPx7, or GPx8. As a result, hydrogen peroxide 
R. Ushioda and K. Nagata
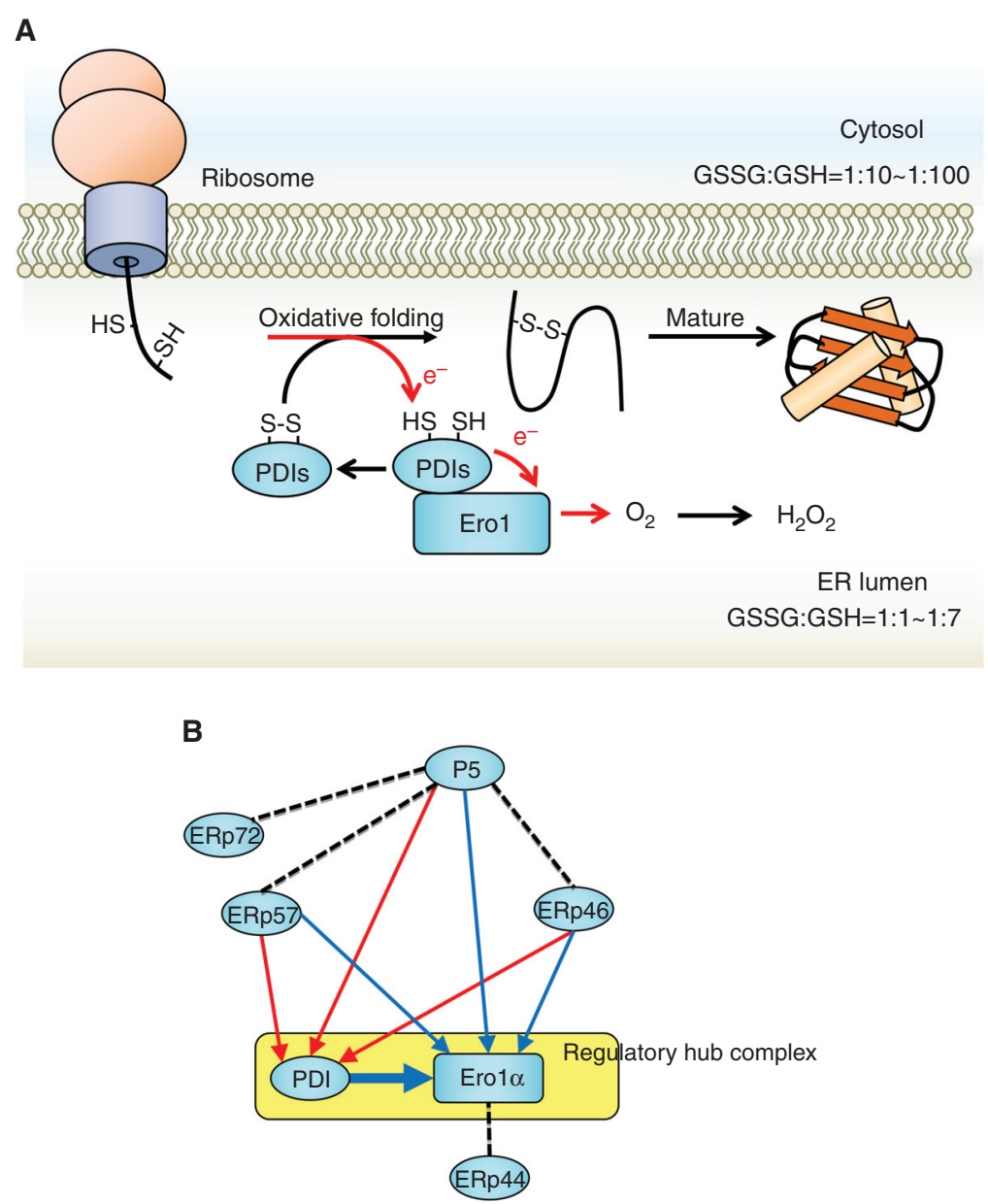

Figure 2. Oxidative folding by Erol $\alpha$ and protein disulfide isomerase (PDI) family proteins. $(A)$ The nascent polypeptide synthesized from the ribosome acquires a proper structure by oxidative folding and is folded into a mature protein. At this time, the PDI family (PDIs) takes electrons $\left(\mathrm{e}^{-}\right)$from the substrate and transfers them to Erol $\alpha$. Next, Ero1 $\alpha$ transfers electrons to molecular oxygen $\left(\mathrm{O}_{2}\right)$ via flavin adenine dinucleotide (FAD), and hydrogen peroxide $\left(\mathrm{H}_{2} \mathrm{O}_{2}\right)$ is produced. Compared with the cytosol, the ER has a high ratio of oxidized glutathione, and this oxidative environment is environmentally favorable for oxidative folding. ( $B)$ The cascade of electron transfer among PDI family proteins (Araki et al. 2013). Red or blue arrows indicate electron transfer to PDI or Erol $\alpha$, respectively. Broken lines indicate the redox-independent interaction or presumed electron transfer.

from Erol $\alpha$ efficiently contributes to oxidative folding (Tavender et al. 2010; Zito et al. 2010; Nguyen et al. 2011). In addition, the Ero1 activity must be strictly controlled to prevent increases in hydrogen peroxide or excess oxidation of substrates. A detailed analysis of the control of Ero1 was previously reported. Interestingly, Erol $\alpha$ monitors the redox state of the ER through an intramolecular disulfide bond and thus controls its own activity. When the
ER becomes oxidative because of hydrogen peroxide accumulation, disulfide bonds are formed in the Ero1 molecule, and the shuttling of electrons to the active center cysteine is restricted in yeast (Sevier et al. 2007; Heldman et al. 2010; Kim et al. 2012) and mammals (Fig. 3; Appenzeller-Herzog et al. 2008, 2010; Baker et al. 2008; Chambers et al. 2010; Wang et al. 2011; Ramming et al. 2016). As a result, the transfer of electrons from PDI to Ero1 is suppressed along 
A

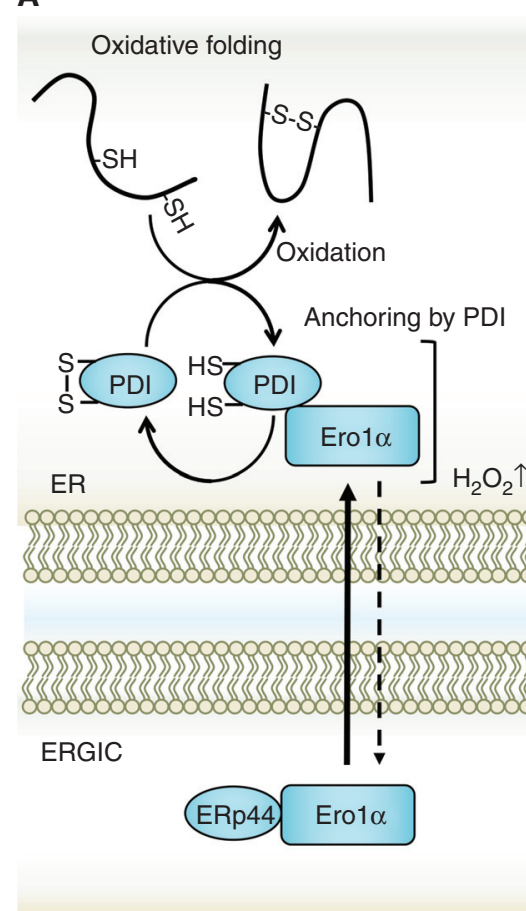

B

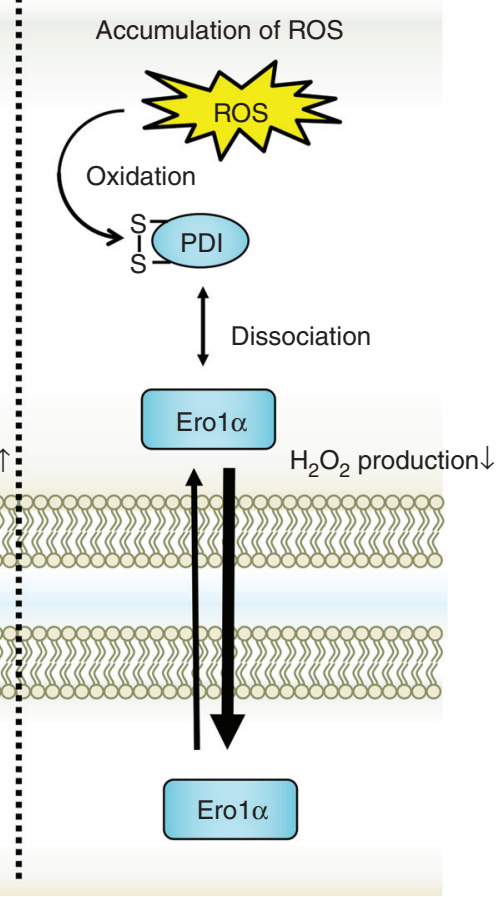

Figure 3. Spatial control of Erol $\alpha$ to protect the endoplasmic reticulum (ER) from oxidative stress. Erol $\alpha$ produces hydrogen peroxide after transferring electrons to oxygen molecules. The accumulation of hydrogen peroxide causes oxidative stress in the ER, which leads to the perturbation of ER homeostasis. For control, Erol $\alpha$ senses an oxidative environment with disulfide bonds possessed by Erol $\alpha$ or protein disulfide isomerase (PDI) and is released from the ER. Ero1 $\alpha$ transferred to the ER-Golgi intermediate compartment (ERGIC) is recycled back to the ER by ERp44.

with hydrogen peroxide production. Ero1 inactivation also limits the availability of its interaction site with PDI, thus reducing the physical interaction between Ero1 and PDI.

Furthermore, Erol $\alpha$ activity is controlled not only by structural regulation through intramolecular cysteines but also by spatial regulation. The ER localization of Erol $\alpha$ is regulated in two steps by PDI and ERp44 (Otsu et al. 2006; Kakihana et al. 2013). Neither Ero1 $\alpha$ nor Ero1 $\beta$ contain any known ER retention signal. Nonetheless, Erol $\alpha$ and Ero1 $\beta$ localize to the ER by forming a complex with PDI. In PDI-knockdown cells, Erol $\alpha$ is mainly localized in the ER-Golgi intermediate compartment (ERGIC). Next, Erol $\alpha$ binds with ERp44 in the ERGIC and is recycled back to the ER together with ERp44. This shuttling of Erol $\alpha$ between the
ER and the ERGIC controls the redox environment of the ER lumen. According to a previous report (Kakihana et al. 2013), the expression of Erol $\alpha$ artificially fused with an ER retention signal increased the GSSG ratio in the ER; this was one answer to the long-standing question of why Erol does not have an ER retention signal. Ero1 $\alpha$ must be fluidly transported from the ER to the ERGIC to maintain a proper redox state in the ER. When the ER is in an excessively oxidized state, the shuttling of electrons caused by the formation of intramolecular disulfide bonds in the ER is restricted, which suppresses the production of hydrogen peroxide by Ero1 $\alpha$. Erol $\alpha$ dissociated from PDI migrates to the ERGIC. Therefore, the network centered on Erol $\alpha-$ PDI must change according to the redox environment of the ER. 
Recent findings have shown that the glutathione environment shifts to a reducing environment because of depletion of calcium ions in the ER (Avezov et al. 2015). Interestingly, the decrease in calcium concentration restricts the mobility of PDI in the ER. PDI preferentially forms a complex with calreticulin, an abundant lectin-type molecular chaperone in the ER, following a decrease in ER calcium concentration. This complex formation decreases the mobility and activity of PDI. The decrease in PDI activity under calcium-depleted conditions inhibits glutathione oxidation and largely influences the redox environment of the ER, shifting it to a reducing environment. Notably, the mobility of the disulfide reductase ERdj5 in the ER is not significantly changed by calcium depletion. Another study reported that other ER stresses, such as tunicamycin treatment, also increase the ratio of reduced glutathione in the ER (Hoseki et al. 2016). These redox shifts are not only phenomenological but also meaningful environmental shifts in the ER, from oxidative reactions to reductive reactions. What is the significance of the reduction reactions in the oxidative ER?

\section{PROTEIN QUALITY CONTROL OF GLYCOPROTEINS BY THE DISULFIDE REDUCTASE ERdj5}

The oxidative environment of the ER is advantageous for forming the disulfide bonds in nascent polypeptides that are necessary for protein maturation and protein stability. In 2008, we found and reported a novel protein, ERdj5, as an ER-resident reductase having disulfide reductase activity in mammalian cells (Ushioda et al. 2008). ERdj5 contains both a J domain and four thioredoxin-like domains, with the catalytic site Cys-X-X-Cys acting as the oxidoreductase, and belongs to the J-domain protein and thioredoxin superfamily. The J domain potentially binds to Hsp70 family proteins and promotes the ATPase activity of Hsp70. Specifically, ERdj5 binds to $\mathrm{BiP}$, a major Hsp70 family protein in the ER, and promotes the ATPase activity of BiP (Cunnea et al. 2003; Hosoda et al. 2003). The four thioredoxin-like domains in ERdj5 may show catalytic activity for disulfide oxidation, isomer- ization, or reduction. In vitro, we detected the disulfide reductase activity of ERdj5 but not oxidative or isomerase activity. Thus, ERdj 5 was the first disulfide reductase found in the ER.

Interestingly, ERdj5 binds to the lectinlike protein EDEM (ER degradation-enhancing $\alpha$-mannosidase-like protein) (Ushioda et al. 2008). Our group first identified EDEM1 as a lectin-like protein recognizing the $\mathrm{N}$-glycan structures of misfolded proteins (Hosokawa et al. 2001). We also reported that EDEM1 is involved in ER-associated degradation (ERAD) (Hosokawa et al. 2001; Molinari et al. 2003; Oda et al. 2003). Further, we and other groups identified EDEM2 (Mast et al. 2005) and EDEM 3 (Hirao et al. 2006) as EDEM family proteins.

ERAD is one of the protein quality-control systems that relocates terminally misfolded proteins from the ER to the cytosol via dislocon channels and degrades them via the ubiquitin/ proteasome system in the cytosol (Vembar and Brodsky 2008; Olzmann et al. 2013; Xu and Ng 2015). In the quality control of $N$-glycosylated proteins, the folding state of proteins is monitored by the glycans of glycoproteins. As shown in Figure 4, the $\mathrm{Glc}_{3} \mathrm{Man}_{9} \mathrm{GlcNAc}_{2}$ structure (Glc: glucose, Man: mannose, GlcNAc: $N$-acetyl-D-glucosamine) is transferred by oligosaccharyltransferase (OST) to the $\mathrm{N}$-glycan motif (Asn-X-Ser/Thr, where $\mathrm{X}$ is any amino acid except Pro) of nascent polypeptides immediately after insertion into the ER lumen (Kelleher and Gilmore 2006; Ruiz-Canada et al. 2009). During retention in the ER, the glycans are trimmed by ER-resident glucosidase and mannosidase. If the retention time of nascent proteins is extended in the ER because of difficulties in their folding, trimming of the $\mathrm{N}$-glycan chains will proceed (Xu and $\mathrm{Ng} 2015$ ), and trimming of the $\mathrm{N}$-glycan chain in the ER can be regarded as a "folding timer." EDEM family proteins recognize proteins with a trimmed glycan $\left(\mathrm{Man}_{6-8}\right)$ of misfolded proteins and recruit the substrates to the ERAD machinery as terminally misfolded proteins. By this ingenious recognition mechanism through EDEM family proteins, proteins that should be degraded as misfolded proteins are segregated and transferred from the productive pathway to the degradation pathway. Final- 


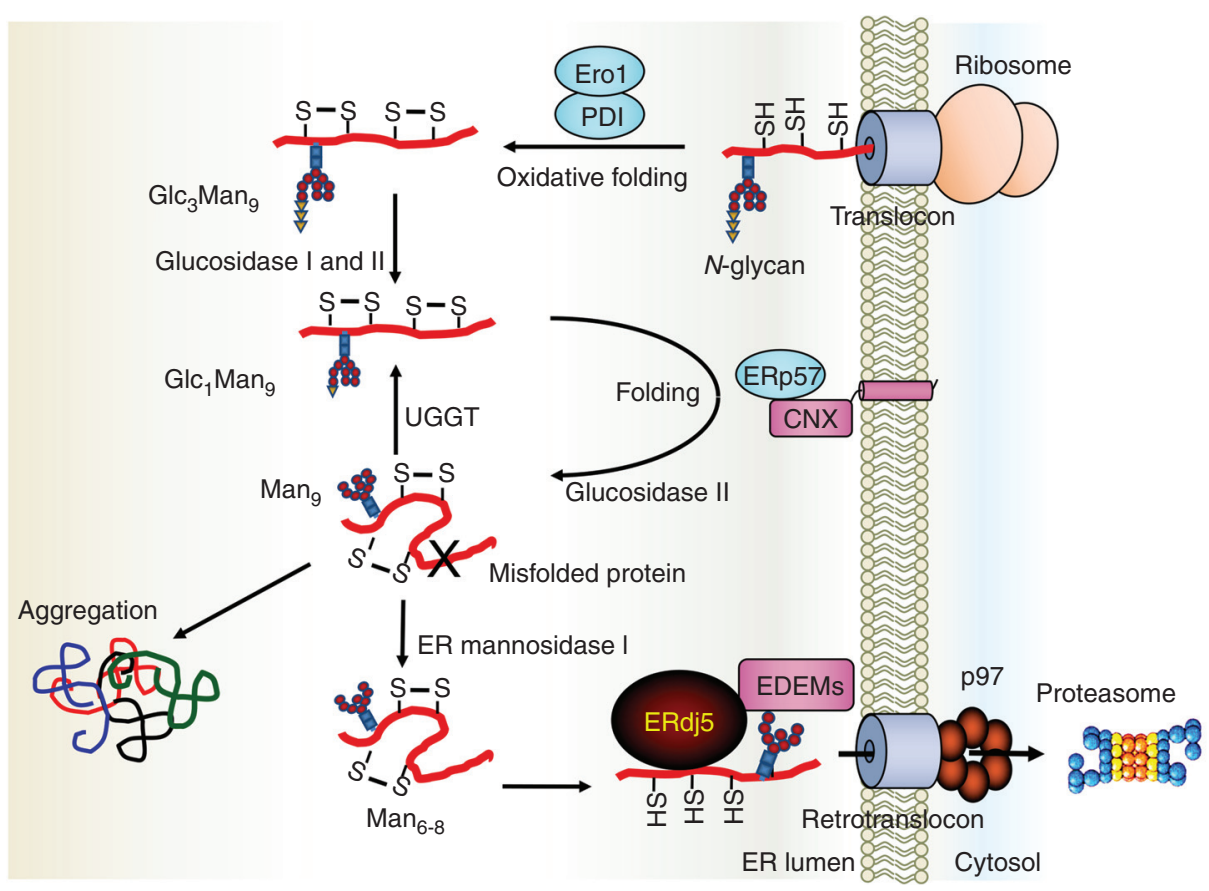

Figure 4. Endoplasmic reticulum (ER)-associated degradation (ERAD) for glycosylated substrates through ERdj5. The nascent protein inserted into the ER is folded by molecular chaperones or oxidoreductases in the ER. However, terminally misfolded proteins should be rapidly dislocated from the ER to the cytosol through the dislocon channel and degraded by the ubiquitin-proteasome system in the cytosol. EDEM recognizes the glycan structure of the misfolded protein and recruits the substrate to the ERAD pathway. ERdj5 binds to EDEM and reduces the disulfide bonds of the misfolded protein recognized by EDEM. The J domain of ERdj5 promotes the ATPase activity of $\mathrm{BiP}$, and $\mathrm{BiP}$ strongly grasps the substrate as ADP-type $\mathrm{BiP}$. Substrate binding to $\mathrm{BiP}$ prevents reoxidation of the substrate, and the substrate is recruited to the dislocon channel. (This figure is based on data from Ushioda et al. 2008.)

ly, ERAD substrates are returned from the ER to the cytosol through the retrograde transport channel (dislocon).

Folded 3D structure and/or oligomeric structure formed and stabilized by disulfide bonds should interfere with prompt retrograde transport of misfolded proteins from the ER through the channel pore owing to possible steric hindrance. We succeeded in showing that the reductase ERdj5 binds to EDEM and cleaves the disulfide bonds of misfolded proteins recognized by EDEM family proteins (Fig. 4; Ushioda et al. 2008; Hagiwara et al. 2011). This result suggested a novel ERAD mechanism in which $\mathrm{N}$-glycan trimming serves to segregate misfolded proteins from the productive pathway via EDEM family proteins and cleavage of disulfide bonds in misfolded proteins by ERdj5 for efficient retrograde transport by reducing the steric hindrance of the proteins.

In a subsequent study, a comprehensive ERdj5 substrate search was performed (Oka et al. 2013). Although the importance of oxidases and isomerases was recognized from previous studies, the contribution of reductases to the folding and/or unfolding of proteins in mammalian cells has not been elucidated. The lowdensity lipoprotein receptor (LDLR) was identified as a substrate of ERdj5. LDLR contains 30 disulfide bonds, and its oxidative folding is accordingly very complicated (Jansens et al. 2002; Gent and Braakman 2004; Pena et al. 2010). In this folding process, ERdj5 reduces the nonnative disulfide bonds of LDLR, which contributes 
to the maturation of LDLR (Oka et al. 2013). This broadens the role of ERdj5 as a reductase in mammalian cells and suggests the importance of this disulfide reductase in protein folding.

\section{ERdj5 IS ALSO INVOLVED IN THE QUALITY CONTROL OF NON-GLYCOPROTEINS}

Many secretory and membrane proteins are glycosylated and maturated in the ER. However, not all proteins are glycosylated. As mentioned above, lectin-type molecular chaperones, such as calnexin and calreticulin, recognize the glycan structure $\left(\mathrm{Glc}_{1} \mathrm{Man}_{9} \mathrm{GlcNAc}_{2}\right)$ and are involved in the quality control of glycoproteins (Ou et al. 1993; Hammond et al. 1994; Jackson et al. 1994). However, the details of the quality control of non-glycoproteins are still unclear. ERdj5 cleaves the disulfide bonds of non-glycosylated ERAD substrates as well as those of glycosylated proteins and promotes their degradation independent of its interaction with EDEM (Ushioda et al. 2013). Generally, the misfolded protein exposes hydrophobic amino acids to the protein surface, and this hydrophobic surface becomes the target of molecular chaperones (Saibil 2013). A non-glycoprotein substrate bound to the major molecular chaperone $\mathrm{BiP}$ in the ER is recruited to ERdj5 via the J domain, and the disulfide bond is cleaved by the reducing activity of ERdj5. Interestingly, glycoprotein substrates are also degraded by the non-glycoprotein pathway under ER stress, during which excess amounts of misfolded glycoproteins likely overwhelm the ERAD pathway for glycoproteins, including EDEMs. Thus, the BiP-ERdj5 pathway for non-glycoprotein ERAD functions as a backup of the glycoprotein substrate pathway consisting of EDEM-ERdj5-BiP coping with multiple misfolded proteins under ER stress (Ushioda et al. 2013).

\section{CALCIUM HOMEOSTASIS IN THE ER THROUGH REDOX CONTROL}

The reducing activity of the disulfide reductase ERdj5, which was first found in the lumen of the ER, plays an important role in protein quality control. We recently clarified that ERdj5 also plays an important role in calcium homeostasis. Intracellular calcium ions act as a second messenger in various life phenomena, including muscle contraction, cellular motility, and vesicular transport (Berridge et al. 2000, 2003). The ER retains $\sim 10,000$ times more calcium ions than the cytosol and acts as a cellular calcium reservoir (Meldolesi and Pozzan 1998a; Hogan and Rao 2007; Michalak et al. 2009). This calcium homeostasis is controlled by the calcium pump and the calcium channel on the ER membrane (Inui et al. 1987; Lai et al. 1988; Miyawaki et al. 1990; Burdakov et al. 2005; Verkhratsky 2005). Interestingly, it has been shown that several pumps and channels are controlled by the redox status of the ER lumen. The reduced IP3 (inositol 1,4,5-triphosphate) receptor (IP3R), which releases calcium ions from the ER to the cytosol, binds to ERp44, a member of the PDI family. This interaction negatively regulates the channel function of ERp44 (Higo et al. 2005). Sarco/ER calcium ATPase (SERCA) family members are P-type ATPases that act as calcium pumps that take calcium ions from the cytosol into the ER in an energy-dependent manner (Burdakov et al. 2005; Verkhratsky 2005). Calcium uptake by SERCA2b is negatively regulated by the oxidase ERp57, which oxidizes the thiol groups on the luminal loop of SERCA2b (Li and Camacho 2004). Moreover, the oxidoreductase TMX1 on the ER membrane also inhibits the activity of SERCA2b (Raturi et al. 2016). When the ER redox environment is oxidative, the release of calcium ions from the lumen of the ER is activated. Uptake into the ER is simultaneously suppressed, and calcium ions in the ER finally decrease. These findings suggest that calcium ions in the ER theoretically decrease when the redox environment in the ER lumen is oxidative. Conversely, in the case of a reductive environment in the ER, the calcium concentration theoretically becomes high. Before the discovery of ERdj5, the mechanism of the reduction involved in calcium regulation was unknown.

We focused on SERCA2b, the most ubiquitously expressed protein in the SERCA family with the widest tissue distribution, and observed the effect of ERdj5 (Ushioda et al. 2016). Only two cysteines on the luminal side of SERCA2b 
form a disulfide bond, and this disulfide formation negatively regulates the pump function. Our analysis confirmed that ERdj5 cleaves its disulfide bond through disulfide reductase activity. We established a system to directly observe the uptake of calcium ions into the ER by SERCA2b and investigated the importance of ERdj5 in calcium ion uptake. Cells were permeabilized with the detergent digitonin, and all the calcium in cells was chelated with EGTA. Next, SERCA-dependent calcium uptake into the ER was observed by adding ATP and calcium ions (the calcium ion probe Fura- 2 was introduced into the ER to measure calcium uptake in the ER). As shown in Figure 5A, the uptake of calcium ions dramatically decreased in ERdj $5^{-1-}$ cells compared with ERdj $5^{+/-}$cells. In addition, in ERdj5-deficient cells, the calcium concentration in the lumen of the ER steadily decreased. These results revealed that ERdj5 cleaves the disulfide bond of SERCA $2 b$ and promotes the pump activity of SERCA2b. A structural approach is needed to understand which step of SERCA2b is promoted by disulfide reduction on the luminal loop of SERCA2b. Furthermore, it is necessary to review and analyze whether only ERdj5 is involved in the activation of SERCA2b through its reduction. Interestingly, Zito et al. (2010) found that SEPN1, a selenoprotein located in the ER, is involved in the activation of SERCA2b (Marino et al. 2015). SEPN1 was suggested to reduce sulfenylated SERCA2b by reducing activity based on the high activity of the active motif, which includes selenocysteine. Although the relationship between ERdj5 and SEPN1 remains unknown, reduction of the reductases ERdj5 and SEPN1 can reduce disulfide-bonded or sulfenic acid-modified SERCA2b cysteines, respectively, for activation of pump activity.

An unexpected characteristic of ERdj5 was revealed by in vitro assays of calcium ion uptake. ERdj5 is usually present as a monomer, but it becomes homomultimerized and dissociates from SERCA2b when the calcium concentration in the ER environment is high (Ushioda et al. 2016). Previous reports showed that PDI forms a complex with a molecular chaperone, such as calreticulin, as the concentration of calcium ions in the ER decreases (Avezov et al. 2015).
Redox-Mediated Mechanisms of ER Homeostasis
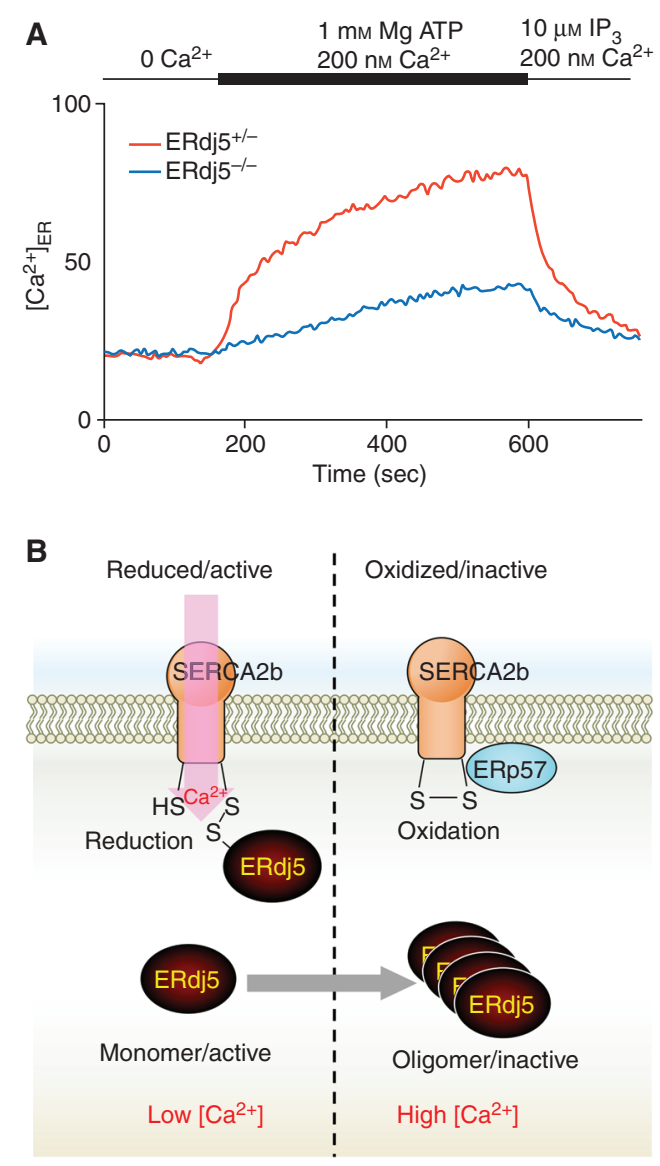

Figure 5. Regulatory mechanism of calcium homeostasis in the endoplasmic reticulum (ER) through SERCA2b and ERdj5. (A) A deficiency of ERdj5 suppresses $\mathrm{Ca}^{2+}$ uptake into the ER through SERCA2b (Ushioda et al. 2016). MEF cells were loaded with Mag-Fura- 2 to estimate ER $\mathrm{Ca}^{2+}$ concentrations. After semi-permeabilized MEFs were treated with EGTA to deplete intra-ER-luminal $\mathrm{Ca}^{2+}$, ATP and $\mathrm{Ca}^{2+}$ were added to examine SERCA2 pump activity. $(B)$ The oxidized (inactive) form of SERCA2b can be converted into the active form by reduction of the disulfide bond in its ER-luminal portion by ERdj5, which facilitates $\mathrm{Ca}^{2+}$ uptake into the ER. Once $\left[\mathrm{Ca}^{2+}\right]_{\mathrm{ER}}$ is recovered, the high $\left[\mathrm{Ca}^{2+}\right]_{\mathrm{ER}}$ causes oligomerization of ERdj5, which inactivates SERCA2b. This feedback regulation by ERdj5 maintains $\mathrm{Ca}^{2+}$ homeostasis in the ER lumen.

This complex formation strongly inhibits PDI activity and attenuates the oxidation of GSH to GSSG by PDI in the ER. The same investigators showed that ERdj5 did not form a complex even 
if the calcium concentration decreased, unlike PDI. These results suggest that the redox environment of the ER may be shifted from an oxidizing environment to a reducing environment under the condition of a low ER calcium ion concentration. As a result, when the calcium concentration in the lumen of the ER decreases, as shown in Figure 5B, monomeric ERdj5 cleaves the disulfide bond of SERCA2b and increases the calcium concentration. On the other hand, once the intraluminal calcium ion concentration in the ER becomes sufficiently high, ERdj5 is released from SERCA2b by forming oligomers, which ceases the activation of calcium uptake by SERCA2b. This sophisticated negative feedback mechanism maintains calcium homeostasis in the ER.

\section{FUTURE PERSPECTIVE}

The ER has been recognized as a site for oxidation reactions, including oxidative folding. However, research from the past decade has revealed the significance of reduction reactions in the ER (Fig. 6). ERdj5 selectively reduces misfolded proteins by binding with EDEM and BiP. Furthermore, monomeric ERdj5 reduces SERCA2b and activates its pump function when the calcium concentration in the ER decreases. In this way, disulfide reductase activity should be

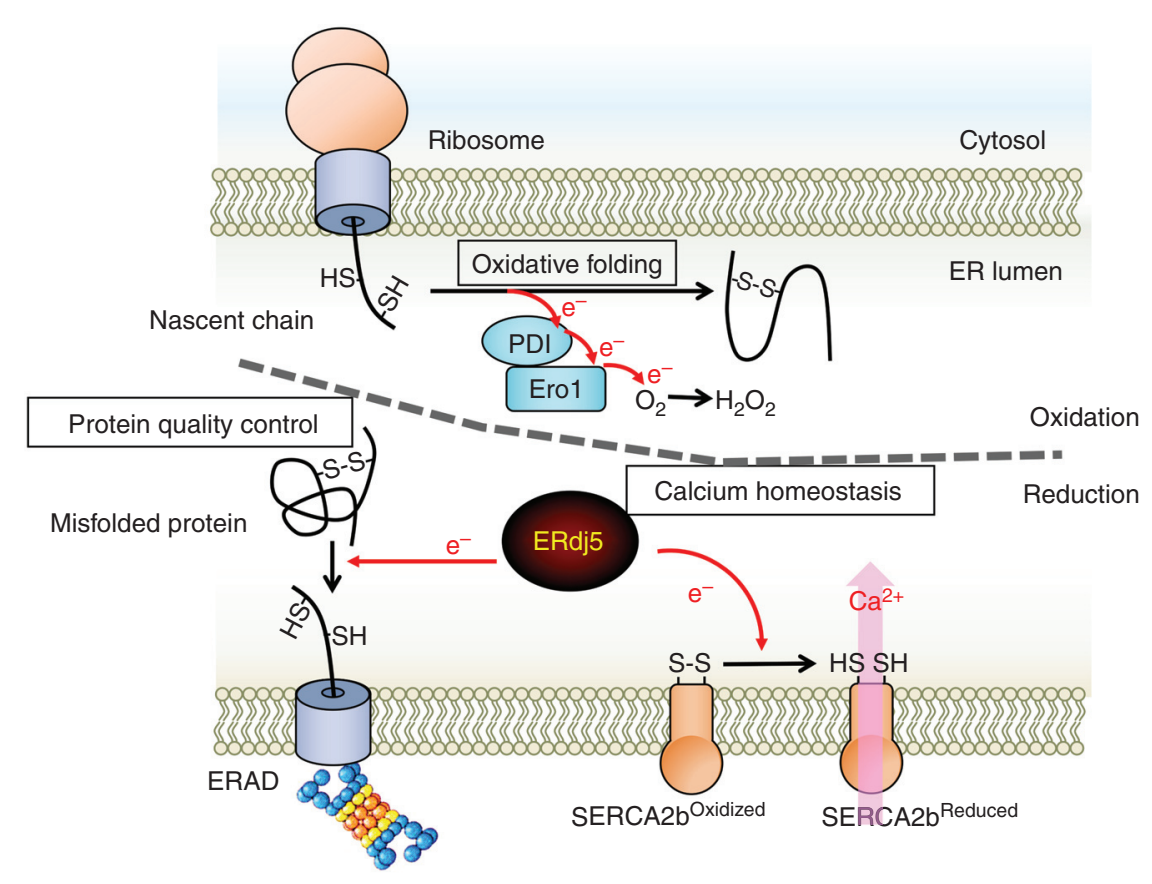

Figure 6. Endoplasmic reticulum (ER) as a site of reduction. The ER is the site of folding of nascent polypeptide chains synthesized from ribosomes. Disulfide bond formation, which is important for structure formation, is catalyzed by protein disulfide isomerase (PDI) family proteins. Disulfide bond formation important for the structure is catalyzed by PDI family proteins, which remove electrons from the substrate. Electrons are ultimately transferred to molecular oxygen via Erol. It is advantageous for oxidative folding that the redox environment of the ER lumen is very oxidative compared with the cytosol, and the ER is regarded as a site of oxidation. ERdj5 was identified as a disulfide reductase in this oxidative environment. The reducing activity of ERdj5 is involved in the disulfide bond cleavage of the terminally misfolded protein in the ERAD pathway and promotes retrograde transport to the cytosol to maintain ER homeostasis. In addition, the calcium pump SERCA2b promotes pump activity by cleavage of the disulfide bond in the lumen of the ER by ERdj5. The reduction reaction is highly involved in calcium homeostasis. 
Redox-Mediated Mechanisms of ER Homeostasis

spatiotemporally and strictly controlled in the lumen of the ER. These results suggest that the reducing environment is transient and local within the oxidative environment of the ER, although the luminal environment of the ER has been thought to be uniformly oxidative.

If the reducing environment is not strictly controlled, it may prevent oxidative folding, and ER homeostasis may be easily disturbed. In the periplasm of Escherichia coli, a typical cytosolic reductase, thioredoxin, transfers electrons to DsbD on the periplasmic membrane. Next, electrons pass across the membrane and are delivered to the periplasmic soluble protein DsbC (Joly and Swartz 1997; Rietsch et al. 1997). Reduced DsbC catalyzes the reduction and isomerization of the substrates folded in the periplasm (Rietsch et al. 1997; Kadokura et al. 2003; Hiniker and Bardwell 2004; Berkmen et al. 2005). However, the DsbC-DsbD system of the ER in eukaryotes has not been elucidated. Recently, reducing molecules, such as GSH, were reported to be transported to provide reductive power in the ER via translocons in the ER membrane (Delaunay-Moisan et al. 2017). Additionally, the Neil Bulleid group showed that inhibition of thioredoxin reductase oxidizes secreted proteins in the ER beyond the ER membranes in mammalian cells (Poet et al. 2017). This result suggests that cytosolic electrons may be transferred into the ER lumen across the ER membrane. However, it remains unknown whether a carrier on the ER membrane brings electrons into the ER. It will be interesting to examine how the localized reduction environment is constructed and will be important for identifying the reduction donor of ERdj5 to clarify its reduction mechanism.

\section{ACKNOWLEDGMENTS}

This work was supported by the Japan Society for the Promotion of Science (JSPS), a Grant-in-Aid for Young Scientists (B) (Grant No. 25840079), Grants-in-Aid for Scientific Research on Innovative Areas (Grant Nos. $15 \mathrm{H} 01545$ and $18 \mathrm{H} 04871$ ), and a grant from the Research Program for CORE Lab of "Five-Star Alliance" in the Network Joint Research Center for Materials and Devices to R.U.

\section{REFERENCES}

Andreu CI, Woehlbier U, Torres M, Hetz C. 2012. Protein disulfide isomerases in neurodegeneration: From disease mechanisms to biomedical applications. FEBS Lett 586: 2826-2834. doi:10.1016/j.febslet.2012.07.023

Appenzeller-Herzog C, Riemer J, Christensen B, Sørensen ES, Ellgaard L. 2008. A novel disulphide switch mechanism in Erol $\alpha$ balances ER oxidation in human cells. EMBO J 27: 2977-2987. doi:10.1038/emboj.2008.202

Appenzeller-Herzog C, Riemer J, Zito E, Chin KT, Ron D, Spiess M, Ellgaard L. 2010. Disulphide production by Erol $\alpha$-PDI relay is rapid and effectively regulated. EMBO J 29: 3318-3329. doi:10.1038/emboj.2010.203

Araki K, Iemura S, Kamiya Y, Ron D, Kato K, Natsume T, Nagata K. 2013. Ero1- $\alpha$ and PDIs constitute a hierarchical electron transfer network of endoplasmic reticulum oxidoreductases. J Cell Biol 202: 861-874. doi:10.1083/jcb. 201303027

Argon Y, Simen BB. 1999. GRP94, an ER chaperone with protein and peptide binding properties. Semin Cell Dev Biol 10: 495-505. doi:10.1006/scdb.1999.0320

Avezov E, Konno T, Zyryanova A, Chen W, Laine R, Crespillo-Casado A, Melo EP, Ushioda R, Nagata K, Kaminski CF, et al. 2015. Retarded PDI diffusion and a reductive shift in poise of the calcium depleted endoplasmic reticulum. BMC Biol 13: 2. doi:10.1186/s12915-014-0112-2

Back SH, Kaufman RJ. 2012. Endoplasmic reticulum stress and type 2 diabetes. Annu Rev Biochem 81: 767-793. doi:10.1146/annurev-biochem-072909-095555

Baker KM, Chakravarthi S, Langton KP, Sheppard AM, Lu H, Bulleid NJ. 2008. Low reduction potential of Erol $\alpha$ regulatory disulphides ensures tight control of substrate oxidation. EMBO J 27: 2988-2997. doi:10.1038/emboj. 2008.230

Bánhegyi G, Csala M, Nagy G, Sorrentino V, Fulceri R, Benedetti A. 2003. Evidence for the transport of glutathione through ryanodine receptor channel type 1. Biochem J 376: 807-812. doi:10.1042/bj20031419

Bass R, Ruddock LW, Klappa P, Freedman RB. 2004. A major fraction of endoplasmic reticulum-located glutathione is present as mixed disulfides with protein. J Biol Chem 279: 5257-5262. doi:10.1074/jbc.M304951200

Berkmen M, Boyd D, Beckwith J. 2005. The nonconsecutive disulfide bond of Escherichia coli phytase (AppA) renders it dependent on the protein-disulfide isomerase, DsbC. J Biol Chem 280: 11387-11394. doi:10.1074/jbc. M411774200

Berridge MJ, Lipp P, Bootman MD. 2000. The versatility and universality of calcium signalling. Nat Rev Mol Cell Biol 1: 11-21. doi:10.1038/35036035

Berridge MJ, Bootman MD, Roderick HL. 2003. Calcium signalling: Dynamics, homeostasis and remodelling. Nat Rev Mol Cell Biol 4: 517-529. doi:10.1038/nrm1155

Birk J, Meyer M, Aller I, Hansen HG, Odermatt A, Dick TP, Meyer AJ, Appenzeller-Herzog C. 2013. Endoplasmic reticulum: Reduced and oxidized glutathione revisited. J Cell Sci 126: 1604-1617. doi:10.1242/jcs.117218

Burdakov D, Petersen OH, Verkhratsky A. 2005. Intraluminal calcium as a primary regulator of endoplasmic 
reticulum function. Cell Calcium 38: 303-310. doi:10. 1016/j.ceca.2005.06.010

Cabibbo A, Pagani M, Fabbri M, Rocchi M, Farmery MR, Bulleid NJ, Sitia R. 2000. ERO1-L, a human protein that favors disulfide bond formation in the endoplasmic reticulum. J Biol Chem 275: 4827-4833. doi:10.1074/jbc. 275.7.4827

Chambers JE, Tavender TJ, Oka OB, Warwood S, Knight D, Bulleid NJ. 2010. The reduction potential of the active site disulfides of human protein disulfide isomerase limits oxidation of the enzyme by Erol $\alpha$. J Biol Chem 285: 29200-29207. doi:10.1074/jbc.M110.156596

Cunnea PM, Miranda-Vizuete A, Bertoli G, Simmen T, Damdimopoulos AE, Hermann S, Leinonen S, Huikko MP, Gustafsson JA, Sitia R, et al. 2003. ERdj5, an endoplasmic reticulum (ER)-resident protein containing Dna] and thioredoxin domains, is expressed in secretory cells or following ER stress. J Biol Chem 278: 1059-1066. doi:10.1074/jbc.M206995200

de Crouy-Chanel A, Richarme G. 2001. Amount and redox state of cytoplasmic, membrane and periplasmic proteins in Escherichia coli redox mutants. Res Microbiol 152: 663669. doi:10.1016/S0923-2508(01)01245-1

Delaunay-Moisan A, Ponsero A, Toledano MB. 2017. Reexamining the function of glutathione in oxidative protein folding and secretion. Antioxid Redox Signal 27: 11781199. doi:10.1089/ars.2017.7148

Dixon BM, Heath SH, Kim R, Suh JH, Hagen TM. 2008. Assessment of endoplasmic reticulum glutathione redox status is confounded by extensive ex vivo oxidation. Antioxid Redox Signal 10: 963-972. doi:10.1089/ars. 2007.1869

Ellgaard L, Helenius A. 2003. Quality control in the endoplasmic reticulum. Nat Rev Mol Cell Biol 4: 181-191. doi:10.1038/nrm1052

Ellgaard L, Ruddock LW. 2005. The human protein disulphide isomerase family: Substrate interactions and functional properties. EMBO Rep 6: 28-32. doi:10.1038/ sj.embor.7400311

Elliott JG, Oliver JD, High S. 1997. The thiol-dependent reductase ERp57 interacts specifically with $\mathrm{N}$-glycosylated integral membrane proteins. J Biol Chem 272: 13849 13855. doi:10.1074/jbc.272.21.13849

Frand AR, Kaiser CA. 1998. The ERO1 gene of yeast is required for oxidation of protein dithiols in the endoplasmic reticulum. Mol Cell 1: 161-170. doi:10.1016/S10972765(00)80017-9

Galligan JJ, Petersen DR. 2012. The human protein disulfide isomerase gene family. Hum Genomics 6: 6. doi:10.1186/ 1479-7364-6-6

Gent J, Braakman I. 2004. Low-density lipoprotein receptor structure and folding. Cell Mol Life Sci 61: 2461-2470. doi:10.1007/s00018-004-4090-3

Ghaemmaghami S, Huh WK, Bower K, Howson RW, Belle A, Dephoure N, O'Shea EK, Weissman JS. 2003. Global analysis of protein expression in yeast. Nature 425: 737741. doi:10.1038/nature02046

Groenendyk J, Zuppini A, Shore G, Opas M, Bleackley RC, Michalak M. 2006. Caspase 12 in calnexin-deficient cells. Biochemistry 45: 13219-13226. doi:10.1021/bi061428z
Gutscher M, Pauleau AL, Marty L, Brach T, Wabnitz GH, Samstag Y, Meyer AJ, Dick TP. 2008. Real-time imaging of the intracellular glutathione redox potential. Nat Methods 5: 553-559. doi:10.1038/nmeth.1212

Hagiwara M, Maegawa K, Suzuki M, Ushioda R, Araki K, Matsumoto Y, Hoseki J, Nagata K, Inaba K. 2011. Structural basis of an ERAD pathway mediated by the ER-resident protein disulfide reductase ERdj5. Mol Cell 41: 432-444. doi:10.1016/j.molcel.2011.01.021

Hammond C, Braakman I, Helenius A. 1994. Role of $\mathrm{N}$-linked oligosaccharide recognition, glucose trimming, and calnexin in glycoprotein folding and quality control. Proc Natl Acad Sci 91: 913-917. doi:10.1073/ pnas.91.3.913

Heldman N, Vonshak O, Sevier CS, Vitu E, Mehlman T, Fass D. 2010. Steps in reductive activation of the disulfidegenerating enzyme Erolp. Protein Sci 19: 1863-1876. doi:10.1002/pro.473

Higo T, Hattori M, Nakamura T, Natsume T, Michikawa T, Mikoshiba K. 2005. Subtype-specific and ER lumenal environment-dependent regulation of inositol 1,4,5-trisphosphate receptor type 1 by ERp44. Cell 120: 85-98. doi:10.1016/j.cell.2004.11.048

Hiniker A, Bardwell JC. 2004. In vivo substrate specificity of periplasmic disulfide oxidoreductases. J Biol Chem 279: 12967-12973. doi:10.1074/jbc.M311391200

Hirao K, Natsuka Y, Tamura T, Wada I, Morito D, Natsuka S, Romero P, Sleno B, Tremblay LO, Herscovics A, et al. 2006. EDEM3, a soluble EDEM homolog, enhances glycoprotein endoplasmic reticulum-associated degradation and mannose trimming. J Biol Chem 281: 9650-9658. doi:10.1074/jbc.M512191200

Hogan PG, Rao A. 2007. Dissecting ICRAC, a store-operated calcium current. Trends Biochem Sci 32: 235-245. doi:10. 1016/j.tibs.2007.03.009

Hoseki J, Oishi A, Fujimura T, Sakai Y. 2016. Development of a stable ERroGFP variant suitable for monitoring redox dynamics in the ER. Biosci Rep 36: e00316. doi:10.1042/ BSR20160027

Hosoda A, Kimata Y, Tsuru A, Kohno K. 2003. JPDI, a novel endoplasmic reticulum-resident protein containing both a BiP-interacting J-domain and thioredoxin-like motifs. J Biol Chem 278: 2669-2676. doi:10.1074/jbc. M208346200

Hosokawa N, Wada I, Hasegawa K, Yorihuzi T, Tremblay LO, Herscovics A, Nagata K. 2001. A novel ER $\alpha$-mannosidase-like protein accelerates ER-associated degradation. EMBO Rep 2: 415-422. doi:10.1093/embo-reports/ kve084

Hwang C, Sinskey AJ, Lodish HF. 1992. Oxidized redox state of glutathione in the endoplasmic reticulum. Science 257: 1496-1502. doi:10.1126/science.1523409

Inui M, Saito A, Fleischer S. 1987. Purification of the ryanodine receptor and identity with feet structures of junctional terminal cisternae of sarcoplasmic reticulum from fast skeletal muscle. J Biol Chem 262: 1740-1747.

Jackson MR, Cohen-Doyle MF, Peterson PA, Williams DB. 1994. Regulation of MHC class I transport by the molecular chaperone, calnexin (p88, IP90). Science 263: 384-387. doi:10.1126/science.8278813

Jansens A, van Duijn E, Braakman I. 2002. Coordinated nonvectorial folding in a newly synthesized multidomain 
protein. Science 298: 2401-2403. doi:10.1126/science. 1078376

Jessop CE, Watkins RH, Simmons JJ, Tasab M, Bulleid NJ. 2009. Protein disulphide isomerase family members show distinct substrate specificity: P5 is targeted to BiP client proteins. J Cell Sci 122: 4287-4295. doi:10.1242/jcs. 059154

Joly JC, Swartz JR. 1997. In vitro and in vivo redox states of the Escherichia coli periplasmic oxidoreductases DsbA and DsbC. Biochemistry 36: 10067-10072. doi:10.1021/ bi9707739

Kadokura H, Katzen F, Beckwith J. 2003. Protein disulfide bond formation in prokaryotes. Аnпu Rev Biochem 72: 111-135. doi:10.1146/annurev.biochem.72.121801.161459

Kakihana T, Araki K, Vavassori S, Iemura S, Cortini M, Fagioli C, Natsume T, Sitia R, Nagata K. 2013. Dynamic regulation of Erol $\alpha$ and peroxiredoxin 4 localization in the secretory pathway. J Biol Chem 288: 29586-29594. doi:10.1074/jbc.M113.467845

Kelleher DJ, Gilmore R. 2006. An evolving view of the eukaryotic oligosaccharyltransferase. Glycobiology 16: 47R-62R. doi:10.1093/glycob/cwj066

Kim S, Sideris DP, Sevier CS, Kaiser CA. 2012. Balanced Ero1 activation and inactivation establishes ER redox homeostasis. J Cell Biol 196: 713-725. doi:10.1083/jcb. 201110090

Lai FA, Erickson HP, Rousseau E, Liu QY, Meissner G. 1988. Purification and reconstitution of the calcium release channel from skeletal muscle. Nature 331: 315-319. doi:10.1038/331315a0

Lappi AK, Ruddock LW. 2011. Reexamination of the role of interplay between glutathione and protein disulfide isomerase. J Mol Biol 409: 238-249. doi:10.1016/j.jmb. 2011.03.024

Lebeche D, Lucero HA, Kaminer B. 1994. Calcium binding properties of rabbit liver protein disulfide isomerase. Biochem Biophys Res Commun 202: 556-561. doi:10.1006/ bbrc. 1994.1964

Li Y, Camacho P. 2004. $\mathrm{Ca}^{2+}$-dependent redox modulation of SERCA 2b by ERp57. J Cell Biol 164: 35-46. doi:10.1083/ jcb.200307010

Lievremont JP, Rizzuto R, Hendershot L, Meldolesi J. 1997. $\mathrm{BiP}$, a major chaperone protein of the endoplasmic reticulum lumen, plays a direct and important role in the storage of the rapidly exchanging pool of $\mathrm{Ca}^{2+}$. J Biol Chem 272: 30873-30879. doi:10.1074/jbc.272.49.30873

Lucero HA, Kaminer B. 1999. The role of calcium on the activity of ERcalcistorin/protein-disulfide isomerase and the significance of the C-terminal and its calcium binding. A comparison with mammalian protein-disulfide isomerase. J Biol Chem 274: 3243-3251. doi:10.1074/ jbc.274.5.3243

Lucero HA, Lebeche D, Kaminer B. 1998. ERcalcistorin/protein-disulfide isomerase acts as a calcium storage protein in the endoplasmic reticulum of a living cell. Comparison with calreticulin and calsequestrin. J Biol Chem 273: 9857-9863. doi:10.1074/jbc.273.16.9857

Marciniak SJ, Yun CY, Oyadomari S, Novoa I, Zhang Y, Jungreis R, Nagata K, Harding HP, Ron D. 2004. CHOP induces death by promoting protein synthesis and oxidation in the stressed endoplasmic reticulum. Genes Dev 18: 3066-3077. doi:10.1101/gad.1250704
Redox-Mediated Mechanisms of ER Homeostasis

Margittai E, Low P, Stiller I, Greco A, Garcia-Manteiga JM, Pengo N, Benedetti A, Sitia R, Banhegyi G. 2012. Production of $\mathrm{H}_{2} \mathrm{O}_{2}$ in the endoplasmic reticulum promotes in vivo disulfide bond formation. Antioxid Redox Signal 16: 1088-1099. doi:10.1089/ars.2011.4221

Marino M, Stoilova T, Giorgi C, Bachi A, Cattaneo A, Auricchio A, Pinton P, Zito E. 2015. SEPN1, an endoplasmic reticulum-localized selenoprotein linked to skeletal muscle pathology, counteracts hyperoxidation by means of redox-regulating SERCA2 pump activity. Hum Mol Genet 24: 1843-1855. doi:10.1093/hmg/ddu602

Mast SW, Diekman K, Karaveg K, Davis A, Sifers RN, Moremen KW. 2005. Human EDEM2, a novel homolog of family 47 glycosidases, is involved in ER-associated degradation of glycoproteins. Glycobiology 15: 421-436. doi:10.1093/glycob/cwi014

Meldolesi J, Pozzan T. 1998a. The endoplasmic reticulum $\mathrm{Ca}^{2+}$ store: A view from the lumen. Trends Biochem Sci 23: 10-14. doi:10.1016/S0968-0004(97)01143-2

Meldolesi J, Pozzan T. 1998b. The heterogeneity of ER $\mathrm{Ca}^{2+}$ stores has a key role in nonmuscle cell signaling and function. J Cell Biol 142: 1395-1398. doi:10.1083/ jcb.142.6.1395

Michalak M, Groenendyk J, Szabo E, Gold LI, Opas M. 2009. Calreticulin, a multi-process calcium-buffering chaperone of the endoplasmic reticulum. Biochem J 417: 651666. doi:10.1042/BJ20081847

Miyawaki A, Furuichi T, Maeda N, Mikoshiba K. 1990. Expressed cerebellar-type inositol 1,4,5-trisphosphate receptor, $\mathrm{P} 400$, has calcium release activity in a fibroblast $\mathrm{L}$ cell line. Neuron 5: 11-18. doi:10.1016/0896-6273(90) 90029-F

Molinari M, Calanca V, Galli C, Lucca P, Paganetti P. 2003. Role of EDEM in the release of misfolded glycoproteins from the calnexin cycle. Science 299: 1397-1400.

Montero D, Tachibana C, Rahr Winther J, AppenzellerHerzog C. 2013. Intracellular glutathione pools are heterogeneously concentrated. Redox Biol 1: 508-513. doi:10.1016/j.redox.2013.10.005

Nguyen VD, Saaranen MJ, Karala AR, Lappi AK, Wang L, Raykhel IB, Alanen HI, Salo KE, Wang CC, Ruddock LW. 2011. Two endoplasmic reticulum PDI peroxidases increase the efficiency of the use of peroxide during disulfide bond formation. J Mol Biol 406: 503-515. doi:10.1016/j.jmb.2010.12.039

Oda Y, Hosokawa N, Wada I, Nagata K. 2003. EDEM as an acceptor of terminally misfolded glycoproteins released from calnexin. Science 299: 1394-1397.

Oka Ojore Benedict V, Pringle Marie A, Schopp Isabel M, Braakman I, Bulleid Neil J. 2013. ERdj5 is the ER reductase that catalyzes the removal of non-native disulfides and correct folding of the LDL receptor. Mol Cell 50: 793-804. doi:10.1016/j.molcel.2013.05.014

Okazaki Y, Ohno H, Takase K, Ochiai T, Saito T. 2000. Cell surface expression of calnexin, a molecular chaperone in the endoplasmic reticulum. J Biol Chem 275: 3575135758. doi:10.1074/jbc.M007476200

Olzmann JA, Kopito RR, Christianson JC. 2013. The mammalian endoplasmic reticulum-associated degradation system. Cold Spring Harb Perspect Biol 5: a013185. doi:10.1101/cshperspect.a013185 
Otsu M, Bertoli G, Fagioli C, Guerini-Rocco E, Nerini-Molteni S, Ruffato E, Sitia R. 2006. Dynamic retention of Erol $\alpha$ and Ero1 $\beta$ in the endoplasmic reticulum by interactions with PDI and ERp44. Antioxid Redox Signal 8: 274-282. doi:10.1089/ars.2006.8.274

Ou WJ, Cameron PH, Thomas DY, Bergeron JJ. 1993. Association of folding intermediates of glycoproteins with calnexin during protein maturation. Nature 364: 771776. doi:10.1038/364771a0

Pagani M, Fabbri M, Benedetti C, Fassio A, Pilati S, Bulleid NJ, Cabibbo A, Sitia R. 2000. Endoplasmic reticulum oxidoreductin 1-L $\beta(E R O 1-\mathrm{L} \beta)$, a human gene induced in the course of the unfolded protein response. J Biol Chem 275: 23685-23692. doi:10.1074/jbc.M003061200

Pena F, Jansens A, van Zadelhoff G, Braakman I. 2010. Calcium as a crucial cofactor for low density lipoprotein receptor folding in the endoplasmic reticulum. $J$ Biol Chem 285: 8656-8664. doi:10.1074/jbc.M110.105718

Poet GJ, Oka OB, van Lith M, Cao Z, Robinson PJ, Pringle MA, Arnér ES, Bulleid NJ. 2017. Cytosolic thioredoxin reductase 1 is required for correct disulfide formation in the ER. EMBO J 36: 693-702. doi:10.15252/ embj.201695336

Pollard MG, Travers KJ, Weissman JS. 1998. Erolp: A novel and ubiquitous protein with an essential role in oxidative protein folding in the endoplasmic reticulum. Mol Cell 1: 171-182. doi:10.1016/S1097-2765(00)80018-0

Ponsero AJ, Igbaria A, Darch MA, Miled S, Outten CE, Winther JR, Palais G, D’Autréaux B, Delaunay-Moisan A, Toledano MB. 2017. Endoplasmic reticulum transport of glutathione by Sec61 is regulated by Erol and Bip. Mol Cell 67: 962-973, e965. doi:10.1016/j.molcel.2017.08.012

Ramming T, Kanemura S, Okumura M, Inaba K, Appenzeller-Herzog C. 2016. Cysteines 208 and 241 in Erola are required for maximal catalytic turnover. Redox Biol 7: 14-20. doi:10.1016/j.redox.2015.11.004

Raturi A, Gutierrez T, Ortiz-Sandoval C, Ruangkittisakul A, Herrera-Cruz MS, Rockley JP, Gesson K, Ourdev D, Lou PH, Lucchinetti E, et al. 2016. TMX1 determines cancer cell metabolism as a thiol-based modulator of ER-mitochondria $\mathrm{Ca}^{2+}$ flux. J Cell Biol 214: 433-444. doi:10.1083/ jcb.201512077

Rietsch A, Bessette P, Georgiou G, Beckwith J. 1997. Reduction of the periplasmic disulfide bond isomerase, DsbC, occurs by passage of electrons from cytoplasmic thioredoxin. J Bacteriol 179: 6602-6608. doi:10.1128/jb. 179.21.6602-6608.1997

Ruiz-Canada C, Kelleher DJ, Gilmore R. 2009. Cotranslational and posttranslational N-glycosylation of polypeptides by distinct mammalian OST isoforms. Cell 136: 272-283. doi:10.1016/j.cell.2008.11.047

Saibil H. 2013. Chaperone machines for protein folding, unfolding and disaggregation. Nat Rev Mol Cell Biol 14: 630-642. doi:10.1038/nrm3658

Salminen A, Kauppinen A, Suuronen T, Kaarniranta K, Ojala J. 2009. ER stress in Alzheimer's disease: A novel neuronal trigger for inflammation and Alzheimer's pathology. J Neuroinflammation 6: 41. doi:10.1186/17422094-6-41

Sevier CS, Qu H, Heldman N, Gross E, Fass D, Kaiser CA. 2007. Modulation of cellular disulfide-bond formation and the ER redox environment by feedback regulation of Ero1. Cell 129: 333-344. doi:10.1016/j.cell.2007.02.039

Tavender TJ, Springate JJ, Bulleid NJ. 2010. Recycling of peroxiredoxin IV provides a novel pathway for disulphide formation in the endoplasmic reticulum. $E M B O J$ 29: 4185-4197. doi:10.1038/emboj.2010.273

Tu BP, Weissman JS. 2002. The FAD- and $\mathrm{O}_{2}$-dependent reaction cycle of Ero1-mediated oxidative protein folding in the endoplasmic reticulum. Mol Cell 10: 983-994. doi:10.1016/S1097-2765(02)00696-2

Tu BP, Ho-Schleyer SC, Travers KJ, Weissman JS. 2000. Biochemical basis of oxidative protein folding in the endoplasmic reticulum. Science 290: 1571-1574. doi:10. 1126/science.290.5496.1571

Ushioda R, Hoseki J, Araki K, Jansen G, Thomas DY, Nagata K. 2008. ERdj5 is required as a disulfide reductase for degradation of misfolded proteins in the ER. Science 321: 569-572. doi:10.1126/science. 1159293

Ushioda R, Hoseki J, Nagata K. 2013. Glycosylation-independent ERAD pathway serves as a backup system under ER stress. Mol Biol Cell 24: 3155-3163. doi:10.1091/mbc. e13-03-0138

Ushioda R, Miyamoto A, Inoue M, Watanabe S, Okumura M, Maegawa KI, Uegaki K, Fujii S, Fukuda Y, Umitsu $\mathrm{M}$, et al. 2016. Redox-assisted regulation of $\mathrm{Ca}^{2+}$ homeostasis in the endoplasmic reticulum by disulfide reductase ERdj5. Proc Natl Acad Sci 113: E6055-E6063. doi:10. 1073/pnas.1605818113

Van der Wal FJ, Oliver JD, High S. 1998. The transient association of ERp57 with $\mathrm{N}$-glycosylated proteins is regulated by glucose trimming. Eur J Biochem 256: 51-59. doi:10.1046/j.1432-1327.1998.2560051.x

Vembar SS, Brodsky JL. 2008. One step at a time: Endoplasmic reticulum-associated degradation. Nat Rev Mol Cell Biol 9: 944-957. doi:10.1038/nrm2546

Verkhratsky A. 2005. Physiology and pathophysiology of the calcium store in the endoplasmic reticulum of neurons. Physiol Rev 85: 201-279. doi:10.1152/physrev. 00004.2004

Wang L, Li SJ, Sidhu A, Zhu L, Liang Y, Freedman RB, Wang CC. 2009. Reconstitution of human Ero1-L $\alpha /$ protein-disulfide isomerase oxidative folding pathway in vitro. Position-dependent differences in role between the $a$ and $\mathrm{a}^{\prime}$ domains of protein-disulfide isomerase. J Biol Chem 284: 199-206. doi:10.1074/jbc.M806645200

Wang L, Zhu L, Wang CC. 2011. The endoplasmic reticulum sulfhydryl oxidase Ero $1 \beta$ drives efficient oxidative protein folding with loose regulation. Biochem J 434: 113-121. doi:10.1042/BJ20101357

Xu C, Ng DT. 2015. Glycosylation-directed quality control of protein folding. Nat Rev Mol Cell Biol 16: 742-752. doi:10. 1038/nrm4073

Zapun A, Darby NJ, Tessier DC, Michalak M, Bergeron JJ, Thomas DY. 1998. Enhanced catalysis of ribonuclease B folding by the interaction of calnexin or calreticulin with ERp57. J Biol Chem 273: 6009-6012. doi:10.1074/jbc.273. 11.6009

Zito E, Melo EP, Yang Y, Wahlander A, Neubert TA, Ron D. 2010. Oxidative protein folding by an endoplasmic reticulum-localized peroxiredoxin. Mol Cell 40: 787-797. doi:10.1016/j.molcel.2010.11.010 


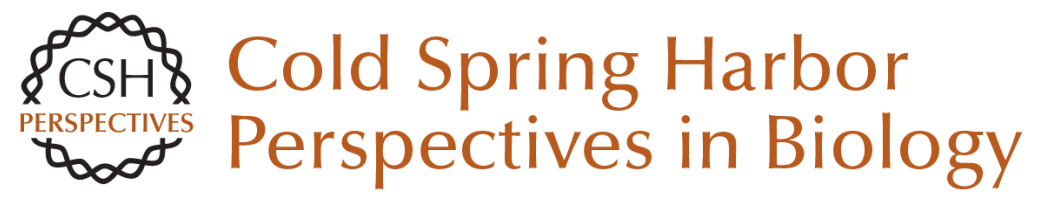

\title{
Redox-Mediated Regulatory Mechanisms of Endoplasmic Reticulum Homeostasis
}

\author{
Ryo Ushioda and Kazuhiro Nagata
}

Cold Spring Harb Perspect Biol 2019; doi: 10.1101/cshperspect.a033910 originally published online November 5, 2018

\section{Subject Collection Protein Homeostasis \\ Proteome-Scale Mapping of Perturbed \\ Proteostasis in Living Cells \\ Isabel Lam, Erinc Hallacli and Vikram Khurana \\ Pharmacologic Approaches for Adapting \\ Proteostasis in the Secretory Pathway to \\ Ameliorate Protein Conformational Diseases Jeffery W. Kelly}

Cell-Nonautonomous Regulation of Proteostasis

in Aging and Disease

Richard I. Morimoto

The Autophagy Lysosomal Pathway and

Neurodegeneration

Steven Finkbeiner

Functional Modules of the Proteostasis Network Gopal G. Jayaraj, Mark S. Hipp and F. Ulrich Hartl

Protein Solubility Predictions Using the CamSol

Method in the Study of Protein Homeostasis Pietro Sormanni and Michele Vendruscolo

Recognition and Degradation of Mislocalized

Proteins in Health and Disease

Ramanujan S. Hegde and Eszter Zavodszky

The Nuclear and DNA-Associated Molecular Chaperone Network

Zlata Gvozdenov, Janhavi Kolhe and Brian C. Freeman
The Amyloid Phenomenon and Its Significance in

Biology and Medicine

Christopher M. Dobson, Tuomas P.J. Knowles and Michele Vendruscolo

A Chemical Biology Approach to the Chaperome

in Cancer--HSP90 and Beyond

Tony Taldone, Tai Wang, Anna Rodina, et al.

Proteostasis in Viral Infection: Unfolding the

Complex Virus-Chaperone Interplay

Ranen Aviner and Judith Frydman

The Proteasome and Its Network: Engineering for

Adaptability

Daniel Finley and Miguel A. Prado

Functional Amyloids

Daniel Otzen and Roland Riek

Chaperone Interactions at the Ribosome Elke Deuerling, Martin Gamerdinger and Stefan G. Kreft

Mechanisms of Small Heat Shock Proteins Maria K. Janowska, Hannah E.R. Baughman, Christopher N. Woods, et al.

Structure, Function, and Regulation of the Hsp90 Machinery

Maximilian M. Biebl and Johannes Buchner

For additional articles in this collection, see http://cshperspectives.cshlp.org/cgi/collection/

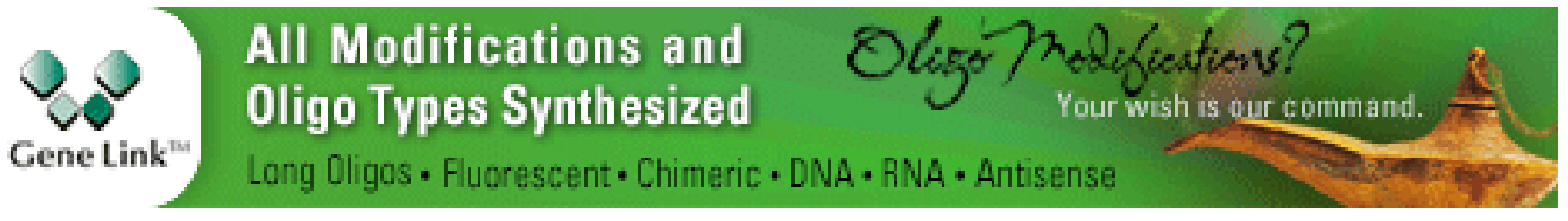


For additional articles in this collection, see http://cshperspectives.cshlp.org/cgi/collection/

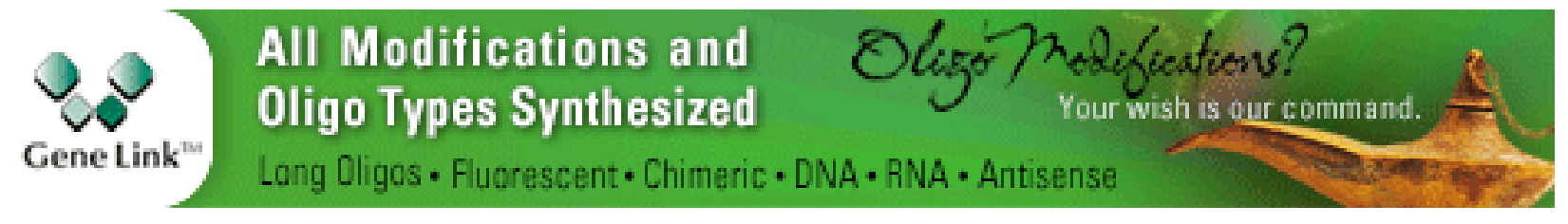

Copyright @ 2019 Cold Spring Harbor Laboratory Press; all rights reserved 